تقارير علمية

\title{
مؤتمر علمي دولي بعنوان: \\ اللغة العربية وتحديات البقاء
}

نظمه مجمع اللغة العربية في القاهرة والمعهد العالمي للفكر الإسلامي

بالتعاون مع مركز الدراسات المعرفية في القاهرة

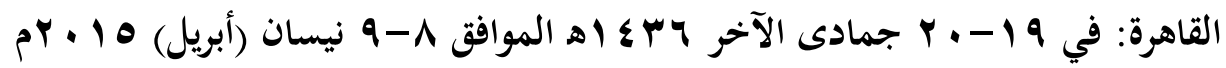

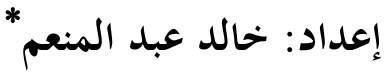

نظم مجمع اللغة العربية في القاهرة والمعهد العالمي للفكر الإسلامي بالتعاون مع مركز

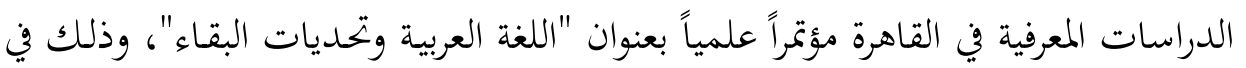

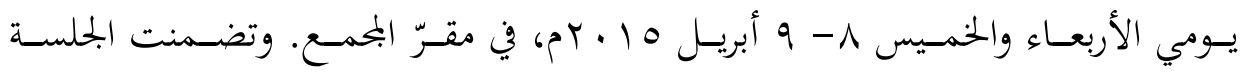

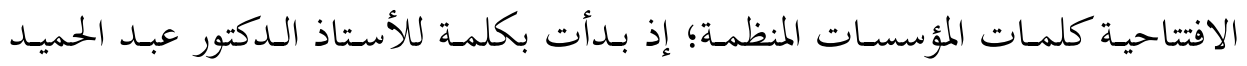

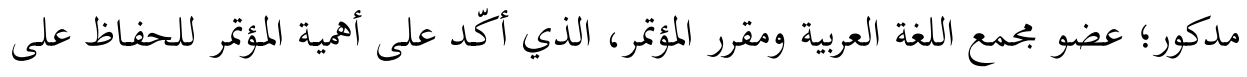

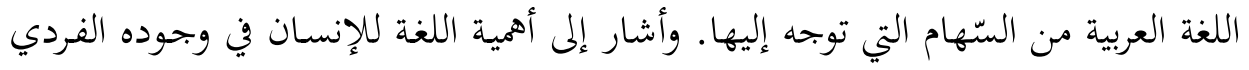

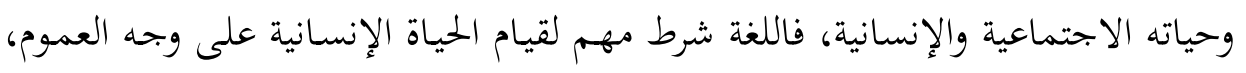

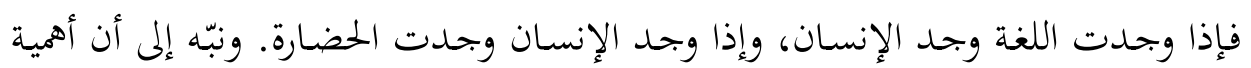
المؤتمر كامنةٌ في محاولة وضع برامج النهوض الإنسان، وإذا وجد الإنسان وجان العربية.

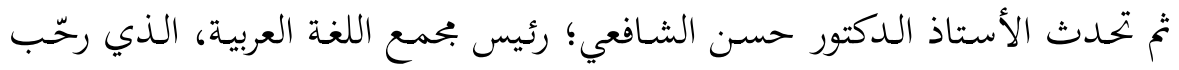

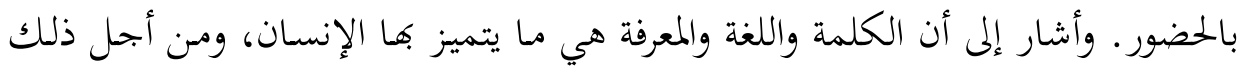

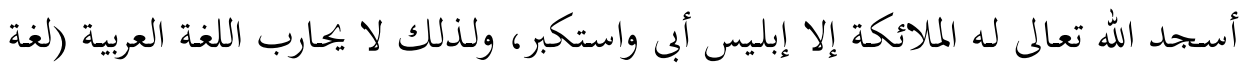

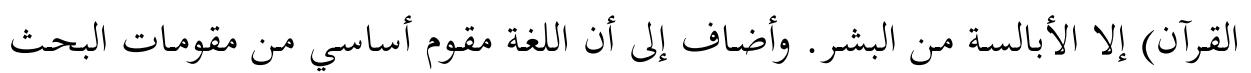

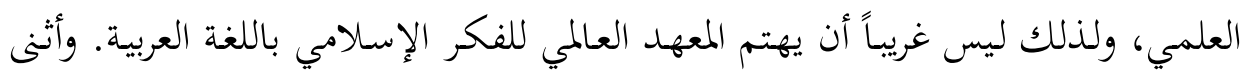




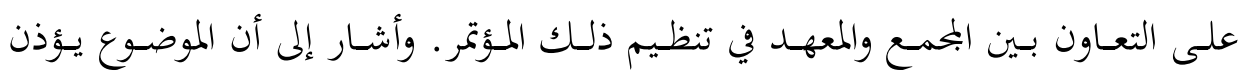

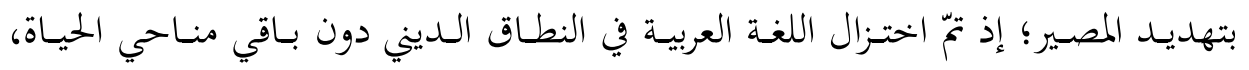

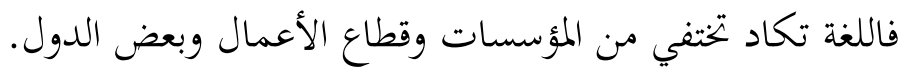

تم جـاءت كلمـة الأستاذ الدكتور عبدـ الحميـد أبو سليمان؛ رئيس المعهـد العـالمي

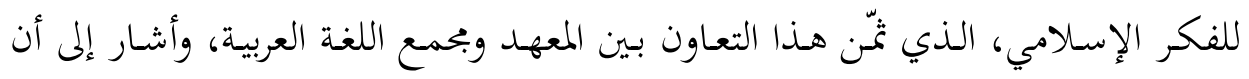

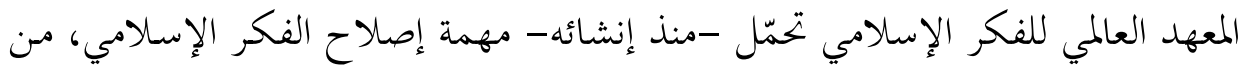

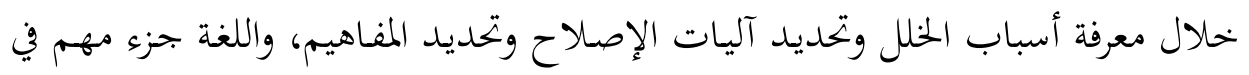

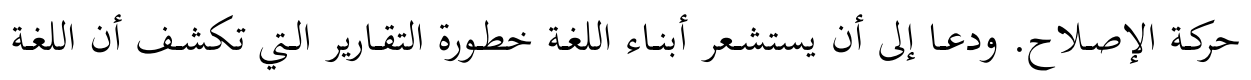

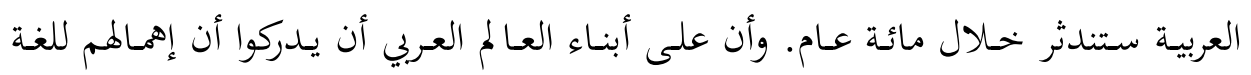

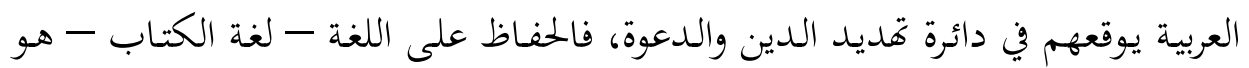
حفاظ على الدعوة إلى الإسلام وكتاب الله العظيم.

ودعا الدكتور عبد الحميد إلى توفير وقفية للاهتمام بالترجمة العلمية والنشر العلمي

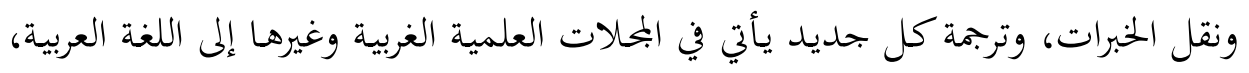

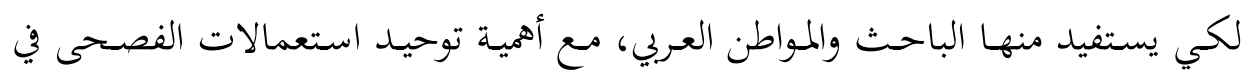

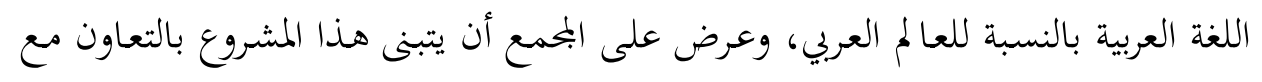

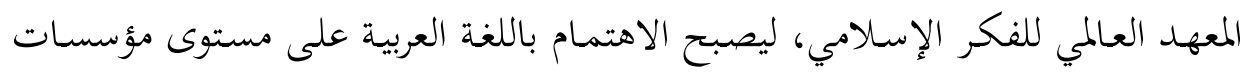
الأمة.

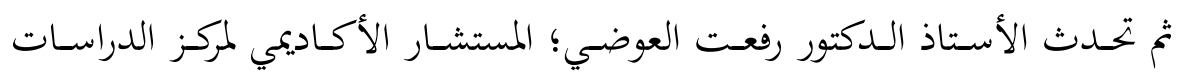

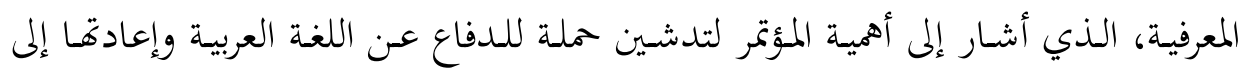

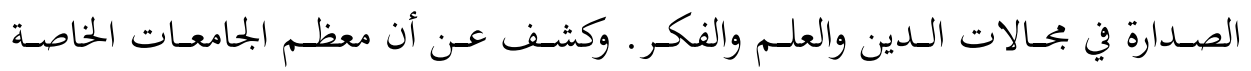

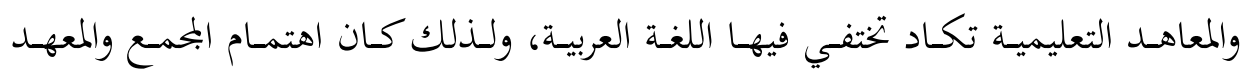

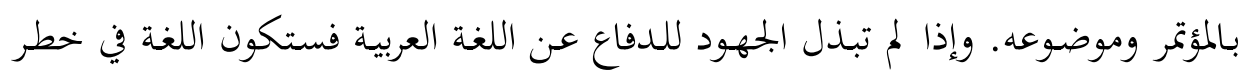
كبير.

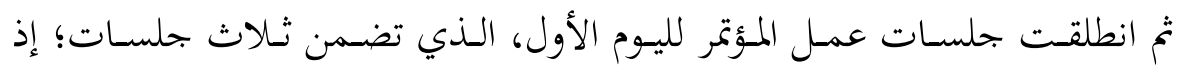

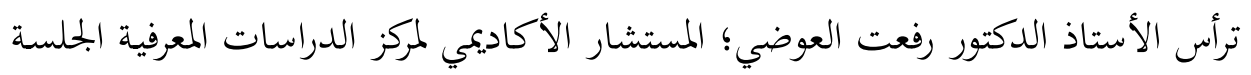


الأولى. وتحدث فيها الأستاذ الدكتور إبراهيم صلاح الهدهد؛ نائب رئيس جامعة الألفاء الأزهر،

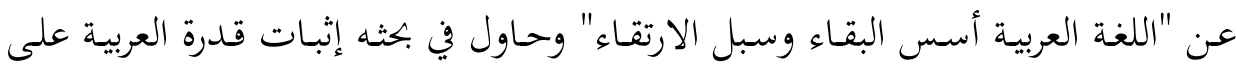

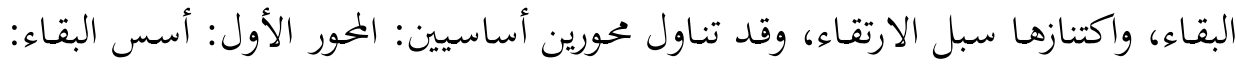

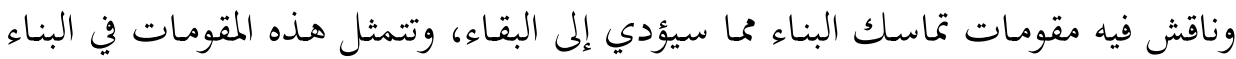

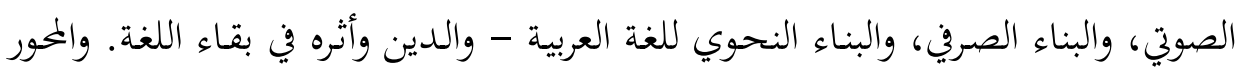

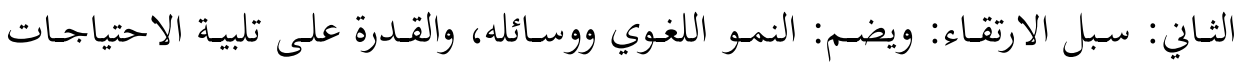

$$
\text { واستيعاب المستجدات، وشهادات من غير العرب للعربية. }
$$

أما البحث الثاني فكان للأستاذ الدكتور عودة خليل أبو عودة؛ عضو بحمع اللغة

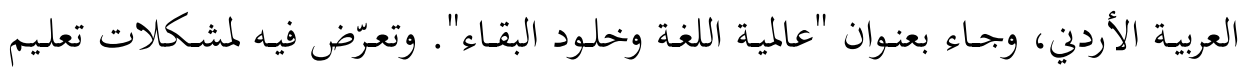

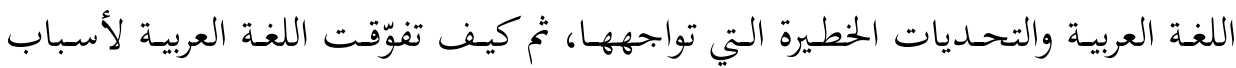

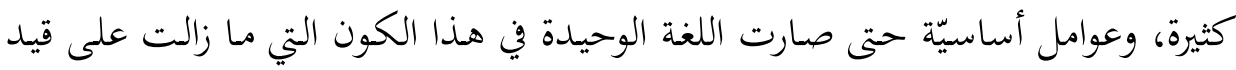

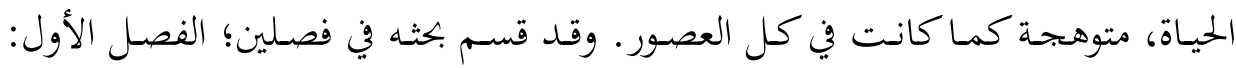

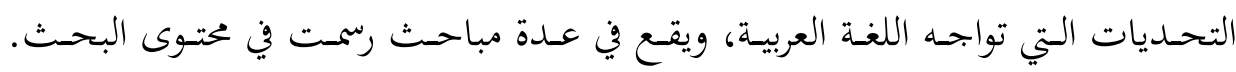

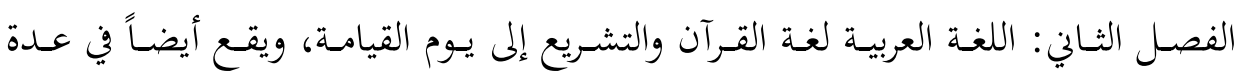
مباحث.

أما الجلسة الثانية التي ترأسها الأستاذ الدكتور إبراهيم صلاح الهدهد، فقد شارك

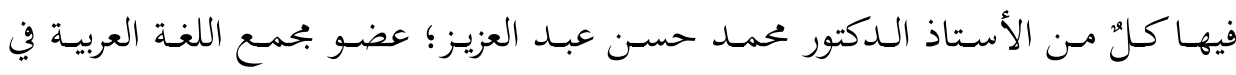

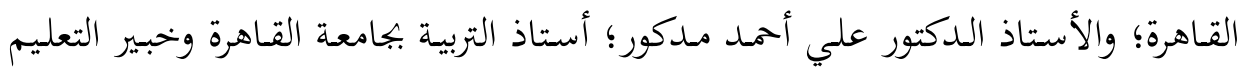

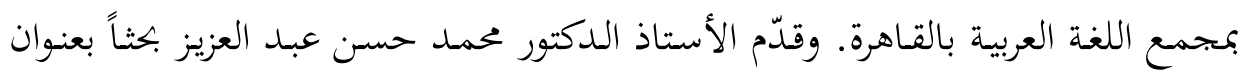

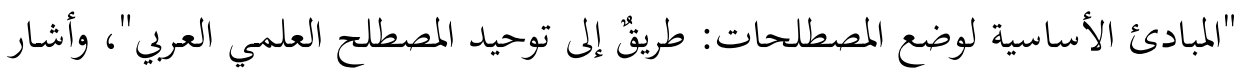

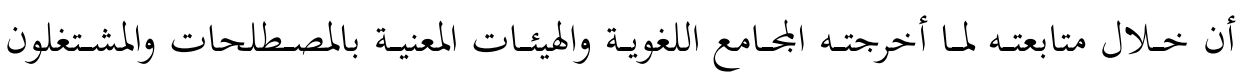

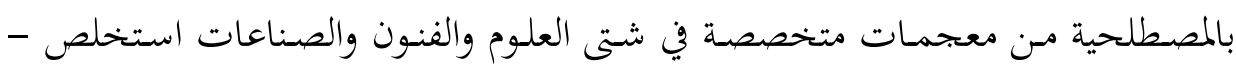

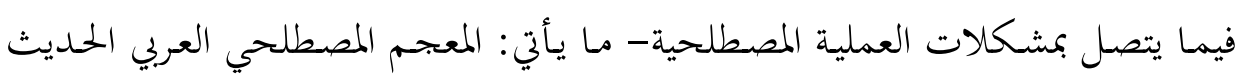

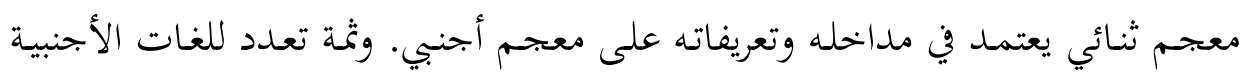

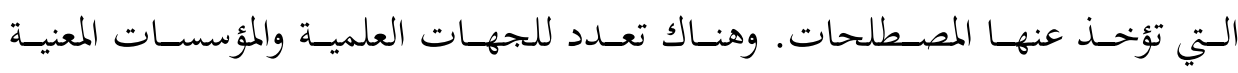




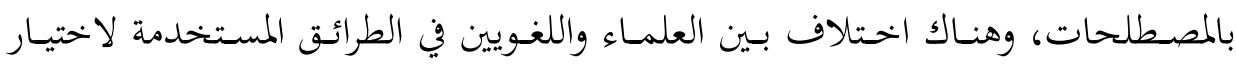

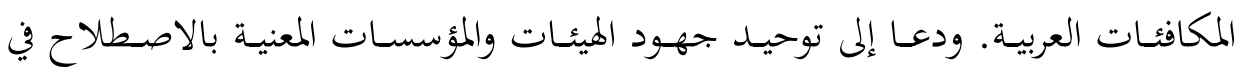

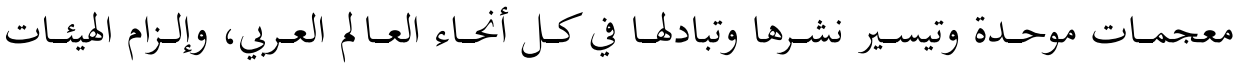

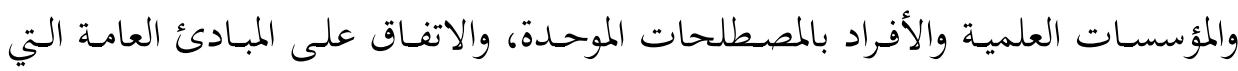

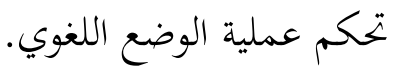

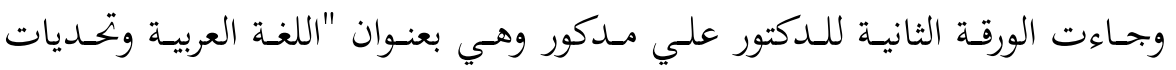

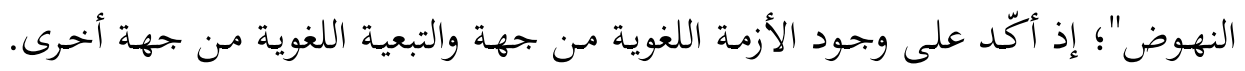

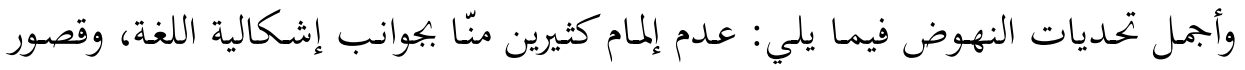

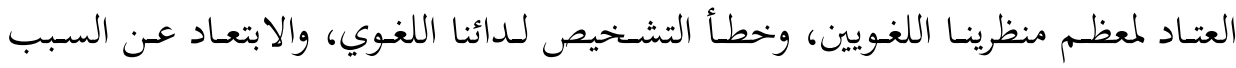

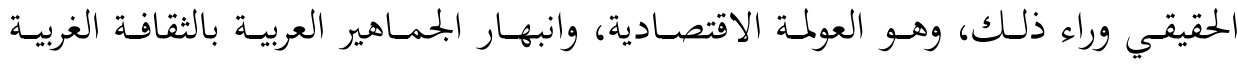

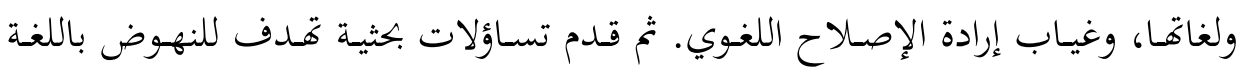

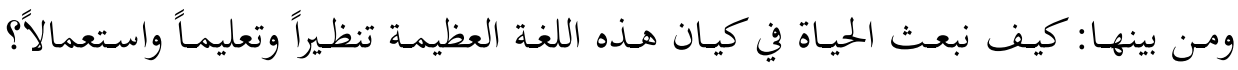

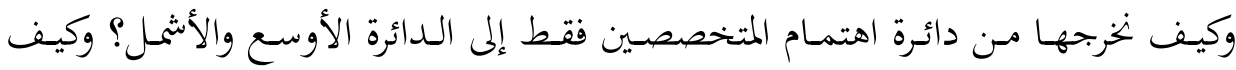

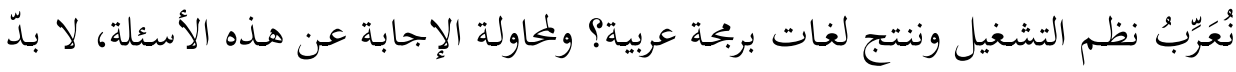

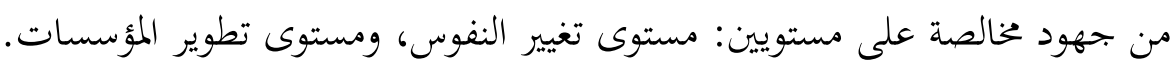

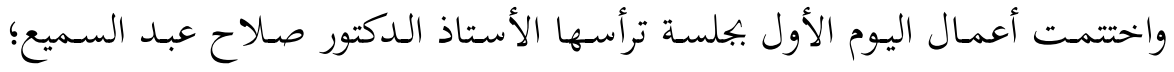

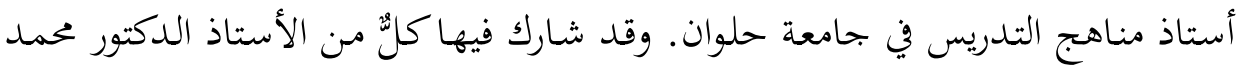

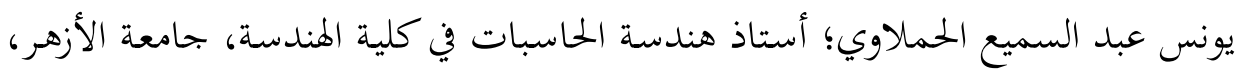

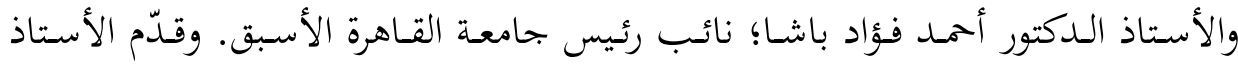

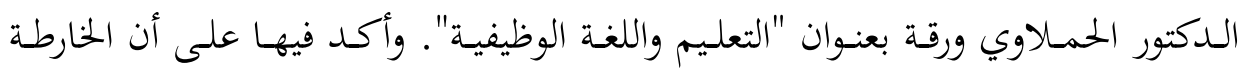

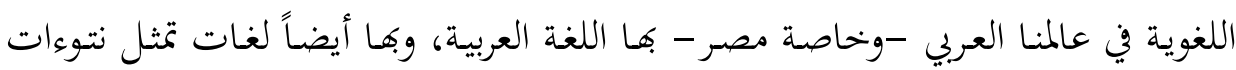

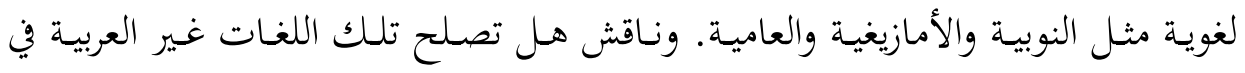

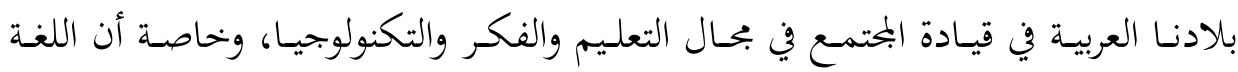

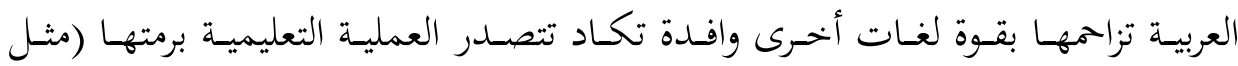

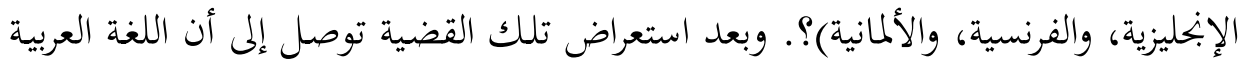


هي اللغة الوحيدة القادرة على قيادة قاطرة التعليم والفكر والتغيير؛ لأفها اللغة الأم، ولغة الفياء الوجدان ولغة القرآن الكريم.

ثم جاءت ورقة الأستاذ الدكتور أحمد فؤاد باشا المعنونة بـلغة العلم العربية وتحديات

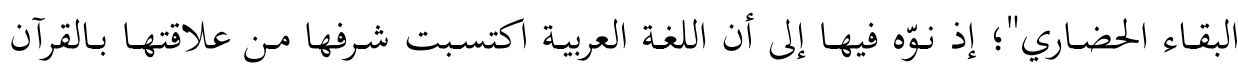

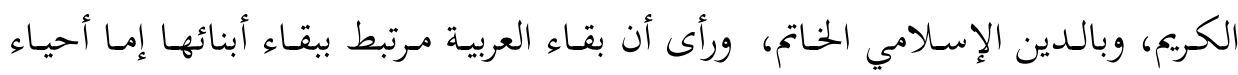

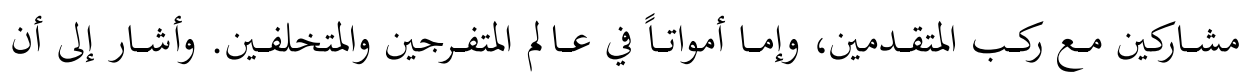

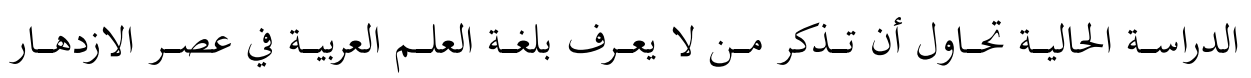

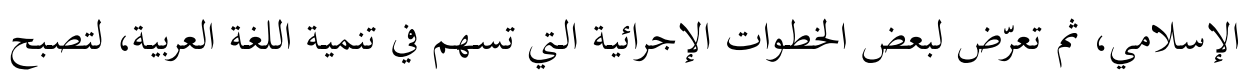
- كما كانت- لغة علم عالمية.

وتواصلت أعمال المؤتمر لليوم الثاني بجلسة صباحية ترأسها الأستاذ الدكتور أحمد فؤاد

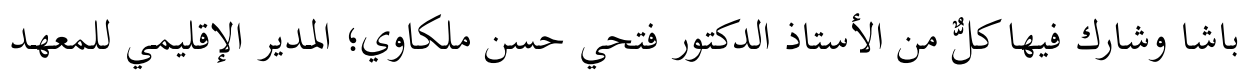

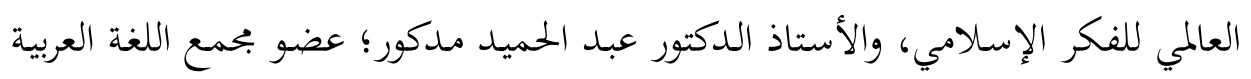

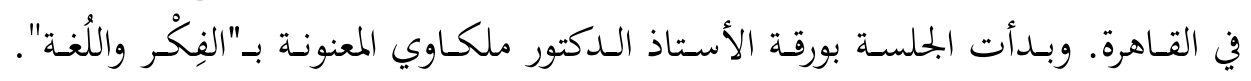

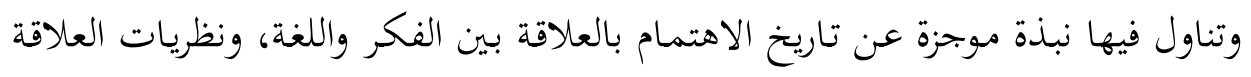

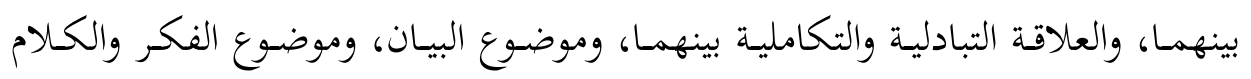

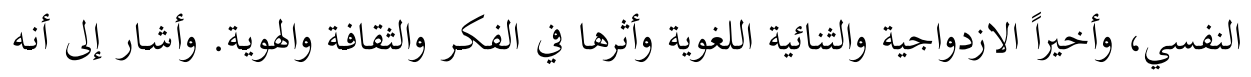

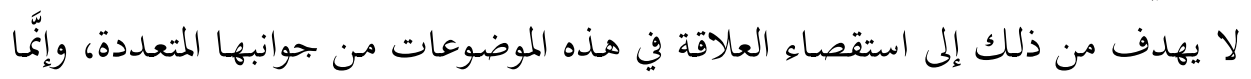

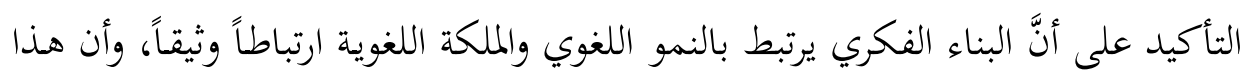

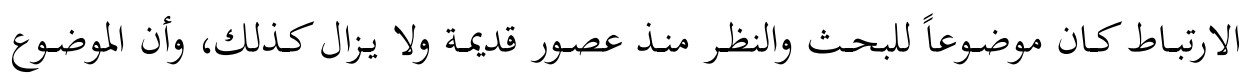
يرتبط بثقافة كل بحتمع وهويته المميّزة له.

وتحدث الأستاذ الدكتور عبد الحميد مدكور في ورقته المعنونة بـ"اللغة العربية والفروض

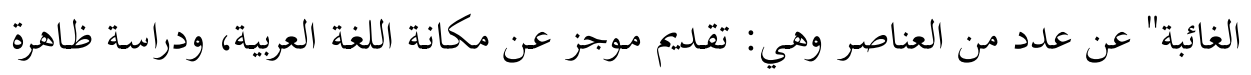

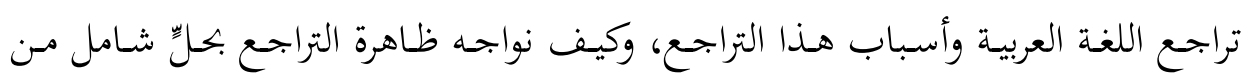

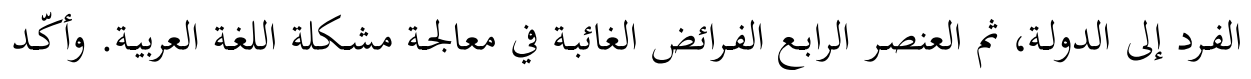


على أن اللغة العربية هي لغة القرآن والعلوم الإسلامية ولغة التراث العلمي بجوانبه المختلفة

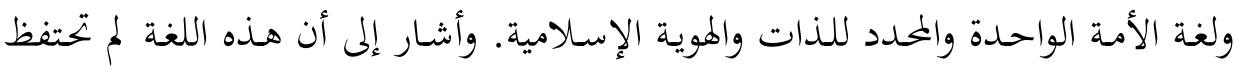

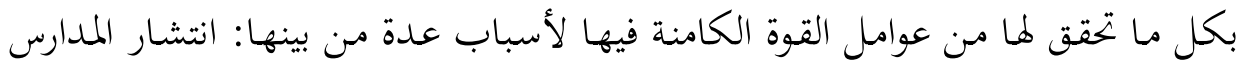
والجامعات التي تدرِّ بلغات أُخرى غير اللغة العربية، وضعف عود المادة العلمية التي تقدم

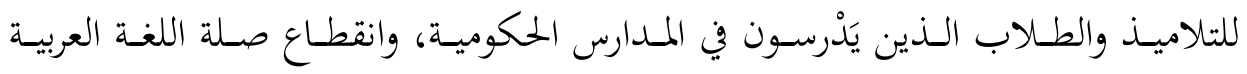
بالدراسـات والبحــوث العلميـة في بحـالات العلـم المختلفـة، والـــعوة إلى مزاحمـة اللغــات المرتبطة ببعض الأعراق غير العربية هذه اللغة كما هو الشأن بالنسبة للأمازيغية والكردية والنوبية، وافتقاد اللغة العربية لمشاعر الحمية لها، والغيرة عليها.

أما الجلسة الخامسة التي ترأسها الأستاذ الدكتور محمد حسن عبد العزيز فقد شارك فيها كلٌّ مـن الأستاذ الدكتور مصطفى رجـب؛ العميد الأسبق لكلية التربية في جامعـة سوهاج، والأستاذ الدكتور رائد جميل عكاشة؛ المستشار الأكاديمي للمعهد العالمي للفكر الإسـلامي في الأردن. وجـاءت ورقة الأستاذ الدكتور مصطفى رجـب بعنوان: "تحـديات

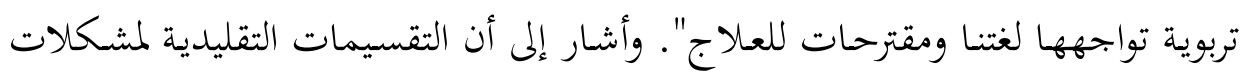
تعليم اللغة العربية تمثل في بعض الأحيان عائقاً منهجياً أمام الكاتبين لعدة أسباب. لمنهاب العها: وجود ما يشبه المسلّمات بين طيات كتب مناهج وطرائق تدريس اللغة العربية، وكذلك

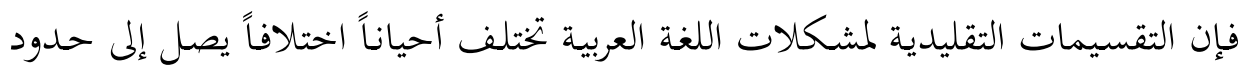

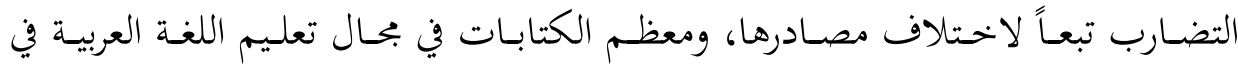
أفلاك ثابتة، وأنماط لا تتغير، كتدريس اللغة العربية بطريقة الوحدة وطريقة الفروع، وتقسيم

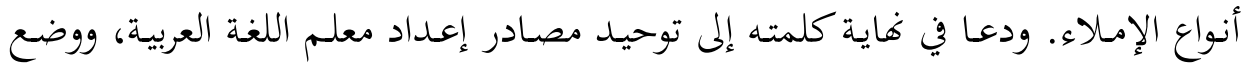
خطة مدروسة عاجلة لتعريب التعليم الجامعي، ووضع ضوابط قانونية أكثر صرامة وإلزاماً

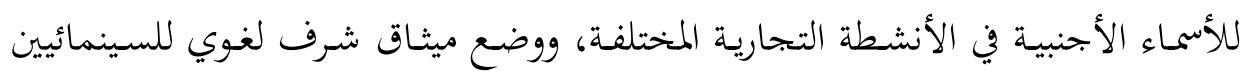
والإعلاميين بوجه عام.

ثم جاءت ورقة الأستاذ الدكتور رائد جميل عكاشة المعنونة بـ"السياسة اللغوية ودورها في النهوض باللغة العربية" ونوّه إلى أنه لا بدّ للمؤسسات أن تتبنى منهجية ورؤية قادرة 
على إحداث فِعل الوجود من خهلال ما يُسمى بالسياسة اللغوية والتخطيط اللغوي؛ إذ إذهاء

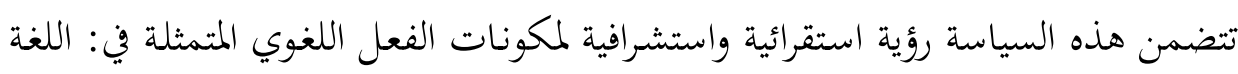

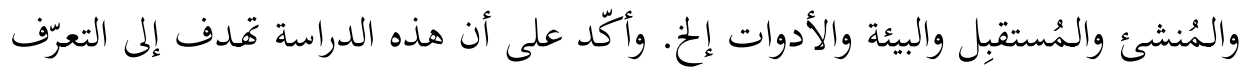

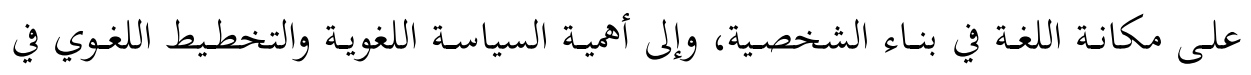

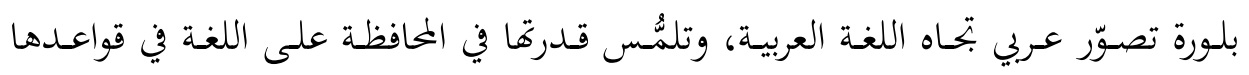

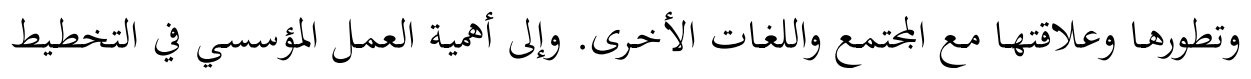

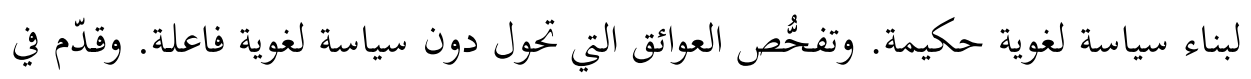
فاية حديثة مقترحات عملية لبناء سياسة لغوية ناجعة.

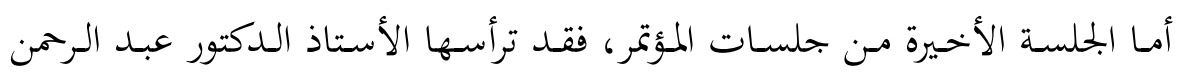

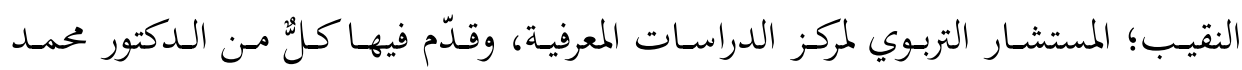

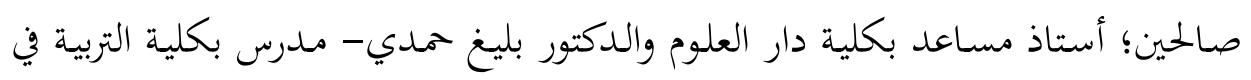

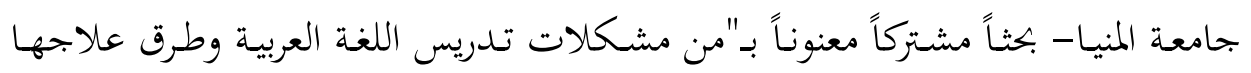

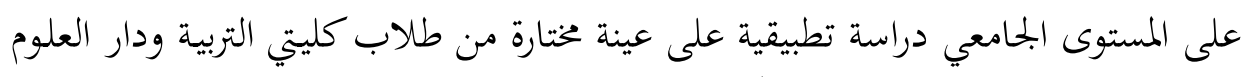

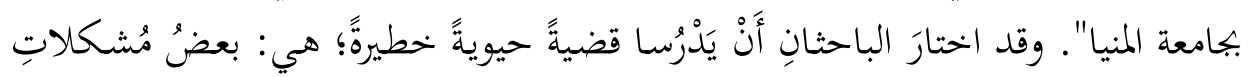

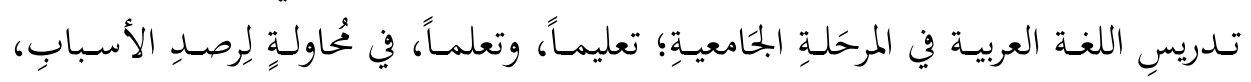

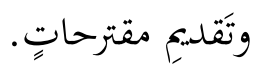

وقد رأى الباحثان وجوبَ تقييد المشكلات المرصودة بالبعضية؛ لصعوبة الإحاطة

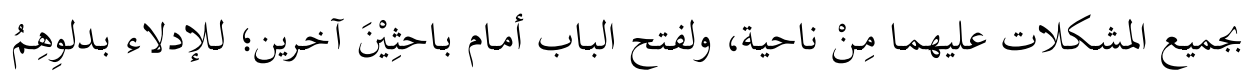

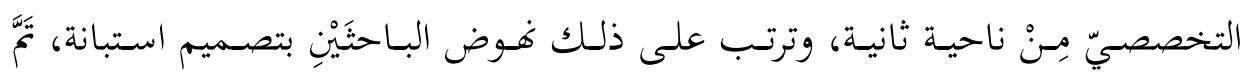

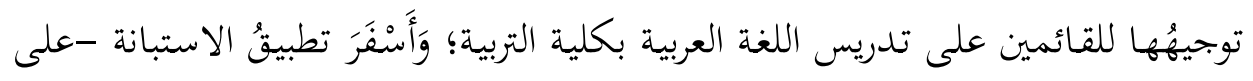

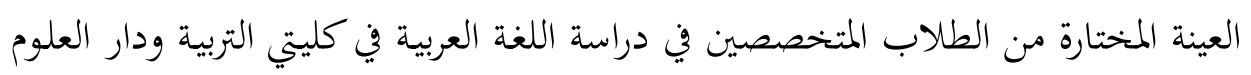

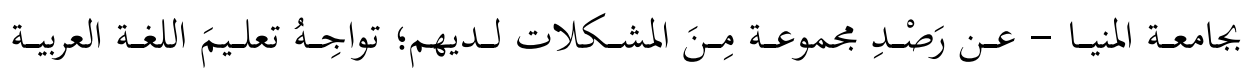

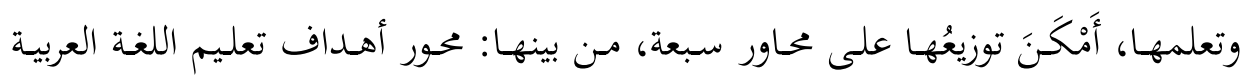

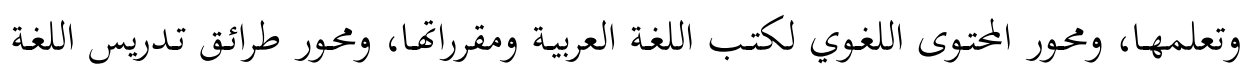

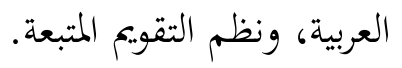


وكـان البحــث الأخسير للـدكتور هيـثم عبـــ الـرحمن عبـــ القـادر؛ دكتـوراه الأديـان

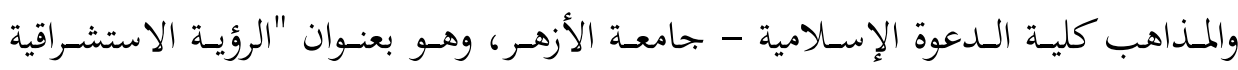

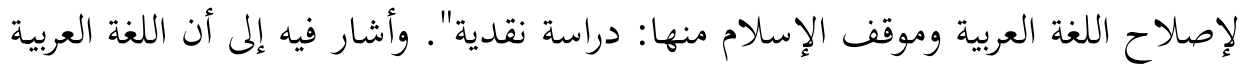

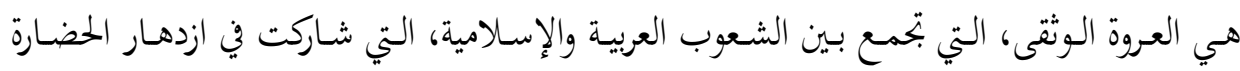

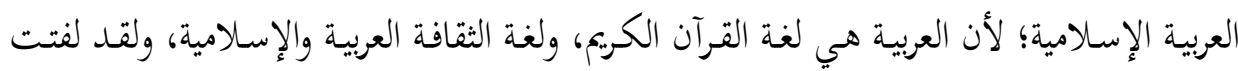

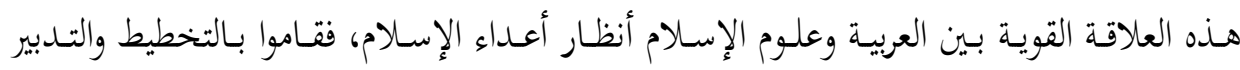

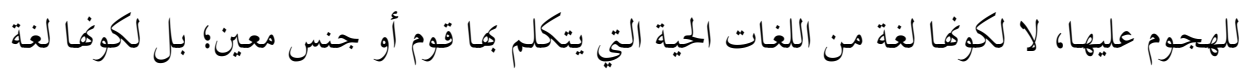

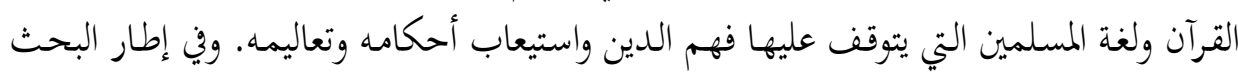

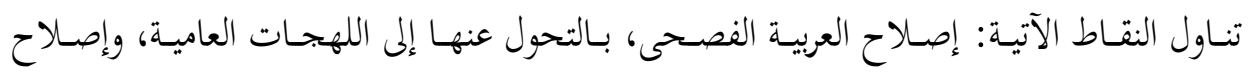

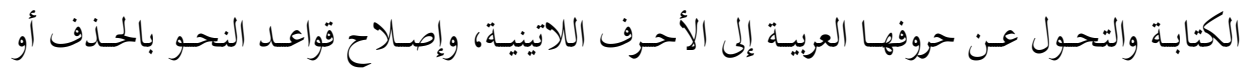

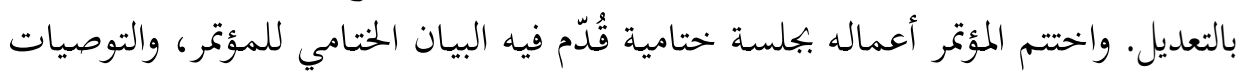
التي جاءت على النحو الآتي:

ا ـ تشجيع المبادرات التي يقوم بها الأفراد والمؤسسات المعنية فيما تقوم به من نشاط محمودٍ لخدمة اللغة العربية، وزيادة نشرها، مع تنسيق الجهود كي يتحقق المزيد من الفائدة. r.العمل على أن تقوم وزارات التربية والتعليم ووزارات التعليم العالي في مصر والبلاد

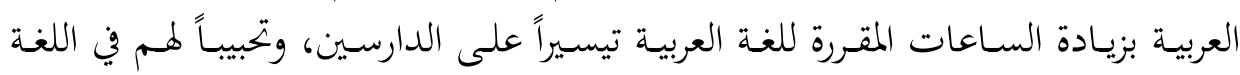

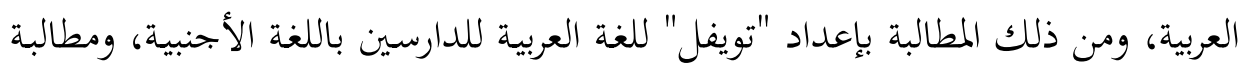

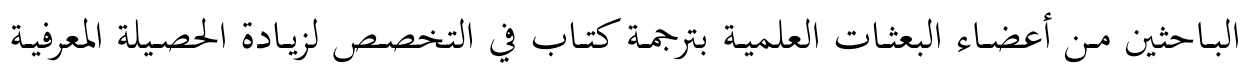

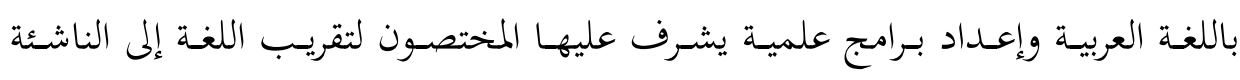
والأطفال، وتهيئتهم لمزيد من التعرف على اللغة العربية واستعمالها. r.إقامة مراكز متخصصة لتعريب العلوم، أسوة بما هو موجود من مراكز التعريب التي تعنى بالعلوم الإنسانية. ـ ـيرغب المشـاركون في المؤتمر في تكرار عقد مثل هذه المؤتمرات على فترات زمنيـة متقاربة، مع الدعاية الكافية لما. ه.تعزيز الروابط الثقافية بين المؤسسـات اللغوية، الرسمية منها وغير الرسميـة، لتوحيد الجهود والبناء على ما تم إبخازه، وفي مقدمة هذه المؤسسات المحامع اللغويّة العربيّة. 